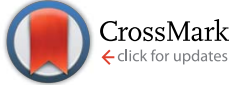
9489
Cite this: J. Mater. Chem. C, 2014, 2 ,

\section{Short lead(II) soaps: from weakly fluorescent crystals to strongly phosphorescent and structurally varied vitreous phases. A thermal, structural and spectroscopic study $\dagger$}

\author{
Francisco J. Martínez-Casado, ${ }^{\text {a }}$ Miguel Ramos-Riesco, ${ }^{\mathrm{b}}$ José A. Rodríguez-Cheda, ${ }^{\mathrm{b}}$ \\ Fabio Cucinotta, ${ }^{c}$ Alejandro Fernández-Martínez, ${ }^{\text {de }}$ Leoncio Garrido, ${ }^{f}$ \\ Emilio Matesanz ${ }^{g}$ and Leonardo Marchese ${ }^{c}$
}

\begin{abstract}
Short lead(॥) alkanoates, from propionate to heptanoate, show a very intricate and reversible thermal behaviour, presenting crystalline phases and three different glass states (regular or amorphous, liquid crystal and rotator glasses) with different degrees of ordering depending on the alkyl chain length. A thorough thermal study was carried out in order to study the different phases and to analyze the thermodynamic parameters. The crystal structures of the compounds were solved by X-ray diffraction, showing similar arrangements of the 2D molecular stacking. PDF analyses of the local order in the glass structures showed shorter first neighbour lead-lead interatomic distances than in the crystalline structures. This allows establishment of a direct relationship between the structure and optical properties. Luminescence properties are, in fact, impressively enhanced in the glass states, passing from weak fluorescence at $77 \mathrm{~K}$ in the crystal phase to strong phosphorescence in the frozen glasses, which persists at room temperature. The high variability and the structure-property relationship described here pave the way for the design of materials with varied luminescence properties based on fine-tuning of their local structure.
\end{abstract}

Received 25th July 2014

Accepted 11th September 2014

DOI: $10.1039 / c 4 t c 01645 a$

www.rsc.org/MaterialsC

\section{Introduction}

${ }^{a}$ MAX IV Laboratory, Lund University, SE-221 00 Lund, Sweden. E-mail: francisco. martinez@maxlab.lu.se

${ }^{b}$ Departamento de Química Física I, Facultad de Ciencias Quimicas, Universidad Complutense, 28040 Madrid, Spain

'Dipartimento di Scienze e Innovazione Tecnologica and Nano-SISTEMI Interdisciplinary Centre, Universitá del Piemonte Orientale "A. Avogadro", via Teresa Michel 11, I-15121 Alessandria, Italy

${ }^{d}$ CNRS, ISTerre, F-38041 Grenoble, France

${ }^{e}$ Univ. Grenoble Alpes, ISTerre, F-38041 Grenoble, France

${ }^{f}$ Departamento de Química Física, Instituto de Ciencia y Tecnología de Polímeros, Consejo Superior de Investigaciones Cientificas (ICTP-CSIC), 28006 Madrid, Spain ${ }^{g}$ Centro de Asistencia a la Investigación - Difracción de Rayos X, Facultad de Ciencias Quimicas, Universidad Complutense, 28040 Madrid, Spain

$\dagger$ Electronic supplementary information (ESI) available: (1) DSC data: thermograms of all the compounds; (2) XRD data: SCXRD and HRPD data; diffraction patterns of $\mathrm{Pb}(\mathrm{C} 7)_{2}$ in the crystal and rotator phases and rotator glass; Rietveld refinement for $\mathrm{Pb}(\mathrm{C} 3)_{2}, \mathrm{~Pb}(\mathrm{C} 5)_{2}$ and $\mathrm{Pb}(\mathrm{C} 6)_{2}$; crystal structures of all the solved compounds; $\mathrm{Pb}-\mathrm{O}$ and $\mathrm{Pb}-\mathrm{Pb}$ distances for $\mathrm{Pb}(\mathrm{C} 3)_{2}, \mathrm{~Pb}(\mathrm{C} 5)_{2}$ and $\mathrm{Pb}(\mathrm{C6})_{2}$; (3) PDF analysis: PDFs obtained for the compounds in the crystal and glass states; comparisons by the type of the phase; PDFs showing the evolution in the glass phases of $\mathrm{Pb}(\mathrm{C} 5)_{2}, \mathrm{~Pb}(\mathrm{C} 6)_{2}$ and $\mathrm{Pb}(\mathrm{C} 7)_{2} ;$ (4) photoluminescence data: PL spectra of the compounds in the crystal and glass phases; (5) C-13 CP/MAS NMR: spectra of $\mathrm{Pb}(\mathrm{C} 7)_{2}$ in the crystal and rotator phases; (6) polarized light microscopy: observations of the liquid crystal phase and liquid crystal glass of $\mathrm{Pb}(\mathrm{C6})_{2}$. CCDC 992161-992166. For ESI and crystallographic data in CIF or other electronic format see DOI: 10.1039/c4tc01645a
Within all the heavy p-block elements, the coordination chemistry of lead(II) compounds is particularly significant due to the variety of structures they show. Despite being a heavy toxic metal, lead can exhibit a variable coordination number and geometry with or without a stereochemically active lone pair of electrons and could therefore show interesting topological arrangements with redox as well as catalytic properties..$^{1-3}$ Moreover, lead(II) exhibits intense optical properties, showing luminescence in the inorganic and metal-organic complexes. ${ }^{4}$ In the last decade, lead(II) compounds have received increasing attention for their potential application as X-ray phosphors and luminescent dopants for light-emitting materials. ${ }^{5-8}$ The $\mathrm{Pb}^{2+}$ ion possesses a $6 \mathrm{~s}^{2}$ outer electron configuration and a large radius that, along with the absence of crystal field stabilization energy effects, can give rise to several coordination geometries and, in turn, supramolecular networks. The peculiar photophysical properties of lead(II) compounds are mainly related to the intrinsic emission that originates from metal-centred (MC) sp triplet states and that depends strongly on the temperature and the lattice interactions. ${ }^{6,8}$

Besides lead 3D-coordination polymers, weak luminescence has been also detected at low temperatures in rather simple $\mathrm{Pb}$ 
salts with a 2D-structure, such as lead(II) decanoate, ${ }^{9}$ which belongs to the lead(II) alkanoate series $\left(\mathrm{Pb}(\mathrm{Cn})_{2}\right.$, where $n$ is the number of carbon atoms). This feature pointed to the possibility of tuning or enhancing the luminescence of lead compounds by obtaining phases with different degrees of disorder, so the interatomic distances and the environment of the $\mathrm{Pb}$ orbitals are modified.

It has been previously demonstrated that it is possible to obtain vitrified phases of rare-earth soaps (or alkanoates) with interesting optical properties. ${ }^{\mathbf{1 0}}$

Most of the metal soaps (or alkanoates) are crystalline 2D coordination polymers in the crystal phase, showing a bilayered arrangement with metal and carboxylate ionic layers and alltrans alkyl chain lipidic alternating layers. ${ }^{\mathbf{1 1}}$ Their structure is such that the salts may present polymorphism and polymesomorphism (several mesophases) from the crystal to the melt. This behaviour is known as the stepwise melting process, referred to a family of organic compounds. The mesophases (ionic liquid crystal and rotator phases, in this case) can be quenched and it is possible to obtain different vitreous phases. ${ }^{12}$ Hence, apart from the regular glass (an amorphous solid state quenched from the isotropic liquid), other glasses ${ }^{\mathbf{1 3 , 1 4}}$ are also possible: (a) plastic crystal glass ${ }^{\mathbf{1 5}}$ (positional order - frozen orientational disorder); (b) liquid crystal glass ${ }^{\mathbf{1 6}}$ (orientational order - frozen positional disorder); (c) condis glass ${ }^{17}$ (positional and orientational order - frozen internal conformational disordered), and (d) rotator glass (positional and orientational order and internal orientational disorder). The latter one is found in lead(II) pentanoate ${ }^{\mathbf{1 8}}$ and implies a state where the alkyl chain rotation movement of the rotator mesophase is frozen, and the all-trans planes of the chains remain in a static random orientation, maintaining their positional and orientational (directional) order.

Here, we report on the existence of three different types of glasses formed from the $\mathrm{Pb}(\mathrm{C} 3)_{2}$ and $\mathrm{Pb}(\mathrm{C} 7)_{2}$ salts: amorphous or regular (from the melt), liquid crystal and rotator glasses, with different types of ordering (see Table 1 ). This variety makes the series of lead(II) alkanoates of great interest from the thermodynamic point of view. In addition, we report the crystal structure of the $\mathrm{Pb}(\mathrm{C} 3)_{2}, \mathrm{~Pb}(\mathrm{C} 5)_{2}$ and $\mathrm{Pb}(\mathrm{C} 6)_{2}$ compounds, being only the ones from $\mathrm{Pb}(\mathrm{C} 4)_{2}$ (ref. 19) and $\mathrm{Pb}(\mathrm{C} 7)_{2}$ (ref. 20) known from previous studies. These structural data of the crystal phase along with the PDF-analysis carried out in the crystal phase and in the different glasses have allowed us to compare the differences in the local structure and, therefore, explain the enhancement of the luminescent properties.

\section{Results and discussion}

\section{The crystal phase and three different glasses}

Thermal behavior of the compounds. The lead(II) alkanoate series $\left(\mathrm{Pb}(\mathrm{Cn})_{2}\right)$ has been analysed by several authors. Members with $n \geq 6$ (ref. 21-27) have been more widely studied because of their interest as mesogens. They present polymesomorphism: an intermediate phase characterized recently as a rotator mesophase, ${ }^{\mathbf{1 8 , 2 8}}$ followed by a smectic A like (or neat) liquid crystal phase (only members with $6 \leq n \leq 12$ ), at a relatively low temperature (around $380 \mathrm{~K}$ ). Regarding the low melting point of these salts, $\mathrm{Pb}(\mathrm{C} 4)_{2}$ to $\mathrm{Pb}(\mathrm{C} 7)_{2}$ are non-volatile ionic solvents since they melt below $398 \mathrm{~K}$, being ionic liquids, ${ }^{29,30}$ and, in particular, $\mathrm{Pb}(\mathrm{C} 6)_{2}$ and $\mathrm{Pb}(\mathrm{C} 7)_{2}$ behave also as ionic liquid crystals under the same criteria. ${ }^{28}$

The shortest members in this study, $\mathrm{Pb}(\mathrm{C} 3)_{2}$ and $\mathrm{Pb}(\mathrm{C} 4)_{2},{ }^{31}$ show only a melting process to the isotropic liquid (IL) from the crystal phase (SII), and easily form glass states, ${ }^{27,31}$ quenched from the isotropic liquid phase $\left(\mathrm{G}_{\mathrm{IL}}\right)$. In fact, metal acetate systems (pure or their binary mixtures) show a strong tendency to form glasses. ${ }^{32-35}$

Lead(II) pentanoate, $\mathrm{Pb}(\mathrm{C} 5)_{2},{ }^{18}$ presents the rotator phase (SI) and two glasses can be obtained from the melt depending on the cooling rate: (a) a regular glass $\left(\mathrm{G}_{\mathrm{IL}}\right.$, similar to one of the shortest members) cooling fast (above $40 \mathrm{~K} \mathrm{~min}^{-1}$, approx.), and (b) a rotator glass $\left(\mathrm{G}_{\mathrm{I}}\right.$, which presents the frozen structure of the intermediate rotator phase), at slower cooling rates.

In the case of $\mathrm{Pb}(\mathrm{C} 6)_{2}$, the DSC thermograms show a fusion, from the solid to the liquid crystal phase (LC), and a subsequent clearing, to the isotropic liquid. When quenching the melt, the glass state of the liquid crystal phase is obtained $\left(\mathrm{G}_{\mathrm{LC}}\right)$, which shows birefringence under polarizing light microscope observation (see Fig. S18 in the ESI $\dagger$ ).

$\mathrm{Pb}(\mathrm{C} 7)_{2}$, on the other hand, presents the following transitions: solid-to-solid transition (SII-SI), a fusion (SI-LC) and a clearing (LC-IL), all of them already reported. ${ }^{25}$ Moreover, a glass transition was found in the second heating, together with the disappearance of the SII-SI transition, similar to what has been observed in $\mathrm{Pb}(\mathrm{C} 5)_{2}$, having been formed a rotator glass $\left(\mathrm{G}_{\mathrm{I}}\right)$, after quenching the sample.

In all the cases, the thermal behaviour is reversible. The main data of the transitions and DSC thermograms can also be found in the ESI. $\dagger$ A schematic description of the phases that appear in these compounds, their main characteristics, the orders and disorders are also summarized in Table 1.

Structure of the crystal phase (XRD). The crystal phase structures of all the compounds included in this work have been solved and refined. Previously, only the structures of two members of the lead(II) alkanoate series, $\mathrm{Pb}(\mathrm{C} 4)_{2}$ and $\mathrm{Pb}(\mathrm{C} 7)_{2}$, were known. ${ }^{19,20} \mathrm{~Pb}(\mathrm{C} 3)_{2}$ (at $\mathrm{RT}$ ), $\mathrm{Pb}(\mathrm{C} 5)_{2}$ and $\mathrm{Pb}(\mathrm{C} 6)_{2}$ (at $100 \mathrm{~K}$ ) were studied by means of single crystal X-ray diffraction (SCXRD). In addition, these last two compounds were solved at RT by high resolution powder diffraction (HRPD), as well as $\mathrm{Pb}(\mathrm{C} 3)_{2}$, which was re-measured by powder diffraction to confirm the structure found by single crystal diffraction at RT.

All members of the $\mathrm{Pb}(\mathrm{Cn})_{2}$ series present a bilayered structure forming a 2D coordination polymer, as expected from the ones known for other members of the series. ${ }^{19,20}$ Despite belonging to different crystal systems (monoclinic, $P 2_{1} / m$, for $n$ $=3$ and 4 , and triclinic, $P \overline{1}$, for $n \geq 5$ ), the molecular arrangement is the same in every case, so they could be considered isostructural.

Thus, there are two kinds of alkyl chains, corresponding to two existing types of carboxylates: (a) $\mu 3$-carboxylate (with both $\mathrm{O}$ atoms chelating and one of them also coordinating another $\mathrm{Pb}$ atom) and (b) $\mu$ 4-carboxylate (with both oxygen atoms bridging and chelating). The ligands present a hemidirected 
Table 1 Phases and mesophases in the short lead(॥) alkanoates. Orders, disorders and types of glasses

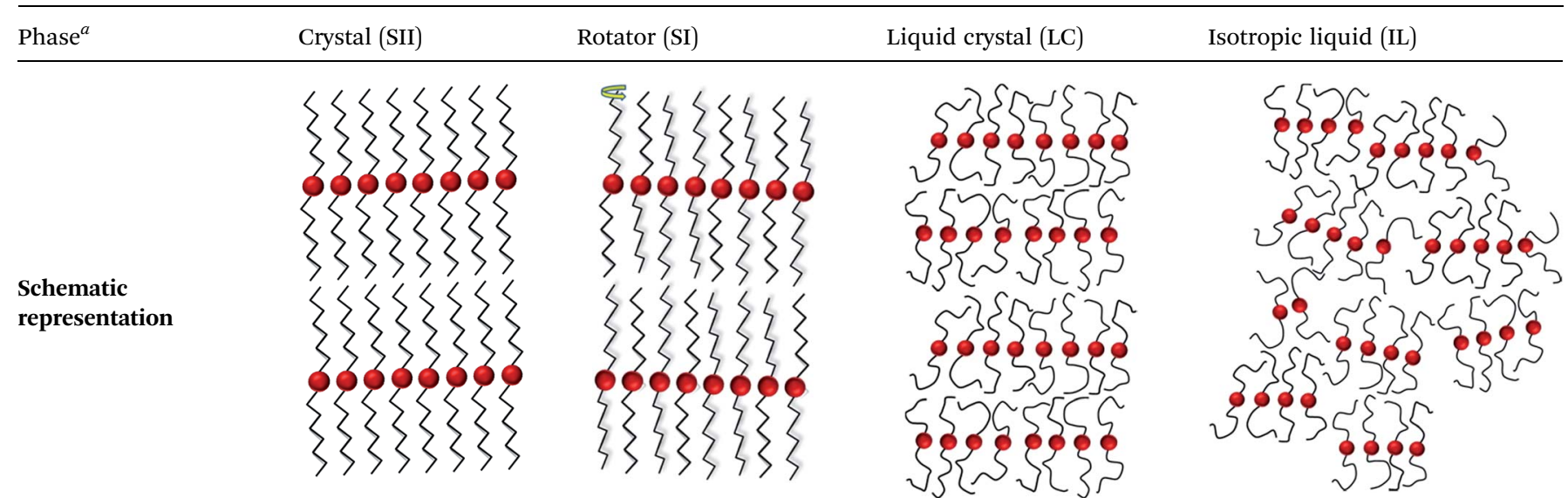

$\begin{array}{lll}\begin{array}{l}\text { Characteristics of the } \\ \text { (meso)phase }\end{array} & \begin{array}{l}\text { Solid phase } \\ \text { Birefringent }\end{array} & \text { Solid mesophase } \\ & \begin{array}{l}\text { Diffraction: } \\ \text { crystalline }\end{array} & \text { Diffraction: crystalline }\end{array}$

Order

All

None

\begin{abstract}
Disorder: dynamic static (glass)
\end{abstract}

Glass

None

Positional, orientational
(directional) and
conformational
(all-trans alkyl chains)

Internal orientational (rotation of the alkyl chains)

Rotator: $\mathrm{G}_{\mathrm{I}}$ $\mathrm{Pb}(\mathrm{C} 5)_{2}, \mathrm{~Pb}(\mathrm{C} 7)_{2}$
Fluid mesophase

Large domains $\rightarrow$ birefringent Diffraction: few peaks $(00 l)$

Positional (domains) and orientational (direction vector perpendicular to the layers)

Positional (fluid) and conformational (alkyl chains "melted")

Liquid crystal: $\mathrm{G}_{\mathrm{LC}}$ $\mathrm{Pb}(\mathrm{C} 6)_{2}$
Fluid phase

Small domains $\rightarrow$ non-birefringent Diffraction: no peaks

Short-range

All

Regular (or amorphous): $\mathrm{G}_{\mathrm{IL}}$ $\mathrm{Pb}(\mathrm{C} 3)_{2}, \mathrm{~Pb}(\mathrm{C} 4)_{2}, \mathrm{~Pb}(\mathrm{C} 5)_{2}$

${ }^{a}$ In the figures, the carboxylates and lead atoms (ionic part) are represented by red balls, whereas the alkyl chains (lipidic part) are represented by black lines.

geometry, with the coordination number of the $\mathrm{Pb}$ atom being seven and with the $\mathrm{O}$ atoms forming a distorted monocapped trigonal prism (Fig. 1 and ESI $\dagger$ ).

The cell parameters at RT for the short lead(II) alkanoates (from $\mathrm{Pb}(\mathrm{C} 3)_{2}$ to $\mathrm{Pb}(\mathrm{C} 7)_{2}$ ) (Table 2 ) show very similar values for the $a$ and $b$ axes and slight variations in the angles, and the logical increase in the $c$ axis (due to the different lengths of the alkyl chain), with the subsequent linear relationship between the $d$-spacing $(00 l)$ and the number of $\mathrm{C}$ atoms of the chain.

PDF analysis of the crystal and glass phases. High-energy $\mathrm{X}$-ray total scattering of the compounds in the crystal and glass phases was carried out. The Pair Distribution Functions (PDFs) provide very clarifying information about the structures and the changes in the atomic distances in each phase for each compound. As an example, the PDFs of the crystal and glass phases of $\mathrm{Pb}(\mathrm{C} 3)_{2}$ are given in Fig. 2. The PDFs for the rest of the compounds and the comparisons between phases are given in detail in the ESI (Fig. S8-S12†).

Thanks to the solved crystal structures, the different atomic distances can be easily identified and, by comparison, they can

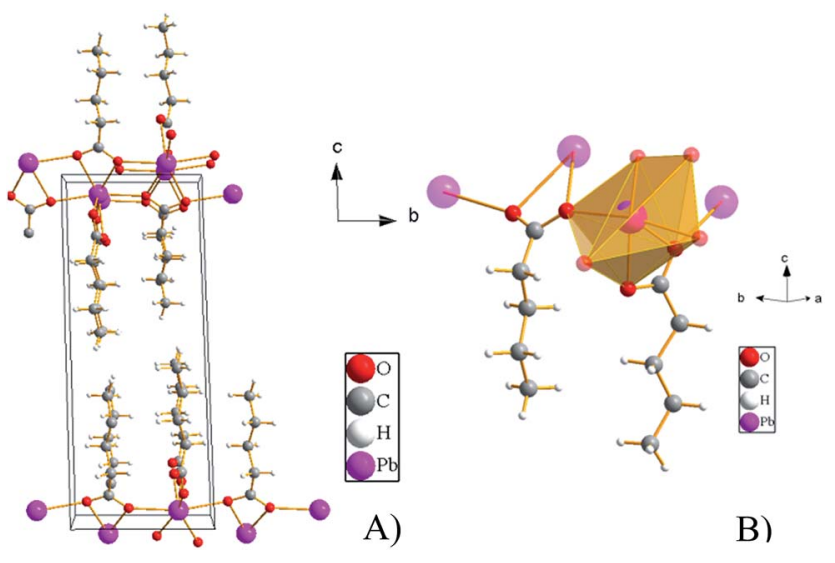

Fig. 1 (A) Crystal structure of $\mathrm{Pb}(\mathrm{C} 5)_{2}$ in the bc projection. (B) Asymmetric unit showing the coordination polyhedron (hemidirected geometry) of the lead(॥) atom (atoms generated by symmetry are drawn semi-transparently). 
Table 2 Cell parameters for the short lead(II) alkanoates at $298 \mathrm{~K}$

\begin{tabular}{|c|c|c|c|c|c|}
\hline$\underline{\text { Data }}$ & $\mathrm{Pb}(\mathrm{C} 3)_{2}{ }^{a}$ & $\mathrm{~Pb}(\mathrm{C} 4)_{2}{ }^{b, c}$ & $\mathrm{~Pb}(\mathrm{C} 5)_{2}{ }^{b}$ & $\mathrm{~Pb}(\mathrm{C} 6)_{2}{ }^{b}$ & $\mathrm{~Pb}(\mathrm{C} 7)_{2}^{a, d}$ \\
\hline Crystal system & Monoclinic & Monoclinic & Triclinic & Triclinic & Triclinic \\
\hline Space group (no.) & $P 2_{1} / m(11)$ & $P 2_{1} / m(11)$ & $P \overline{1}(2)$ & $P \overline{1}(2)$ & $P \overline{1}(2)$ \\
\hline$b(\AA)$ & $7.2100(14)$ & $7.26249(5)$ & $7.27542(7)$ & $7.30782(13)$ & $7.3046(10)$ \\
\hline$c(\AA)$ & $13.036(3)$ & $15.56795(16)$ & $18.09025(15)$ & $20.6733(5)$ & $23.1846(10)$ \\
\hline$\alpha\left(^{\circ}\right)$ & 90 & 90 & $91.2641(12)$ & $91.971(2)$ & $91.610(10)$ \\
\hline$V\left(\AA^{3}\right)$ & $444.32(15)$ & $538.784(8)$ & $630.395(11)$ & $726.98(3)$ & $818.1(2)$ \\
\hline
\end{tabular}

${ }^{a}$ Solved by SCXRD. ${ }^{b}$ Solved by HRPD. ${ }^{c}$ From ref. $19 .{ }^{d}$ From ref. 20.

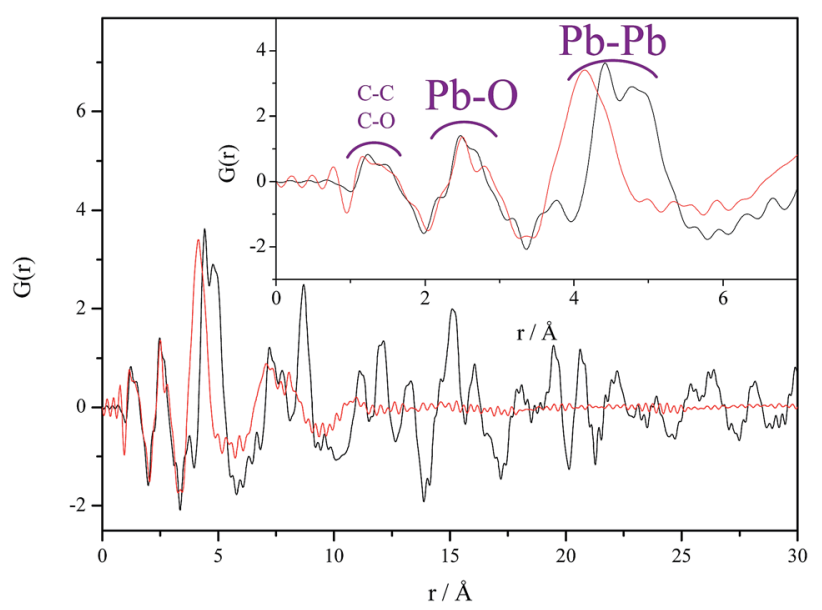

Fig. 2 Pair Distribution Function (PDF) analysis of high-energy $\mathrm{X}$-ray total scattering data for $\mathrm{Pb}(\mathrm{C} 3)_{2}$ in the crystal (black) and regular glass phases (red), with an inset showing the short distance range. The main distances between atoms are shown in the inset.

be inferred for the glass states. First, the long range order, characteristic for periodic structures, is observed for all the crystal compounds, and also for the rotator glass $\left(\mathrm{G}_{\mathrm{I}}\right)$ phase $\left(\mathrm{Pb}(\mathrm{C} 5)_{2}\right.$ and $\left.\mathrm{Pb}(\mathrm{C} 7)_{2}\right)$, whilst the rest of the glass states present only a short range order (up to no more than $10 \AA$ ).

The most important feature found between the crystal and glass phases is the difference in the atomic distances. While the $\mathrm{C}-\mathrm{O}, \mathrm{C}-\mathrm{C}$, and $\mathrm{Pb}-\mathrm{O}$ distances remain mostly unchanged, the largest changes are detected for the $\mathrm{Pb}-\mathrm{Pb}$ distances. In the crystal phase of every salt, the values are around 4.3, 4.7 and 4.9 $\AA$, while for all the glass states (regular, liquid crystal and rotator) the $\mathrm{Pb}-\mathrm{Pb}$ distances appear merged at around $4.15 \AA$.

Despite having different alkyl chain lengths, the same phases are comparable between them, mainly in the first 15-20 A. In the case of the crystal phase, this is expected due to the isostructurality of the compounds. However, this is also observed when comparing the different types of glasses, which present the same distances in the short range order. Thus, almost no differences appear between the regular glass $\left(\mathrm{G}_{\mathrm{IL}}\right)$ and the liquid crystal glass $\left(\mathrm{G}_{\mathrm{LC}}\right)$. In fact, the PDFs of all of these are very similar, showing that in all these cases the ordering in the shortest distances and the bilayered structure is still maintained in $\mathrm{G}_{\mathrm{LC}}$ (glass from a smectic liquid crystal), and also in the supposed "isotropic liquid phase" and its glass $\left(\mathrm{G}_{\mathrm{IL}}\right)$, at least in the short range. The difference could be due to the domain size, which are bigger in the case of the liquid crystal, so that the birefringence and also diffraction can be detected. Another important feature is that the rotator glass $\left(\mathrm{G}_{\mathrm{I}}\right.$, in $\mathrm{Pb}(\mathrm{C} 5)_{2}$ and $\left.\mathrm{Pb}(\mathrm{C} 7)_{2}\right)$ shows the same pattern in the short distances as $\mathrm{G}_{\mathrm{IL}}$ (as seen for $\mathrm{Pb}(\mathrm{C} 5)_{2}$, which presents both). This would imply that the difference between them is the range of ordering: long and short (up to $10 \AA$ ), respectively.

For $\mathrm{Pb}(\mathrm{C} 5)_{2}, \mathrm{~Pb}(\mathrm{C} 6)_{2}$ and $\mathrm{Pb}(\mathrm{C} 7)$, a conversion in time was also observed during the measurements. For $\mathrm{Pb}(\mathrm{C} 5)_{2}$, the regular glass converts into the rotator glass in approximately $20 \mathrm{~min}$. The liquid crystal glass in $\mathrm{Pb}(\mathrm{C} 6)_{2}$ turns partially into a crystal in one hour. The rotator glass in $\mathrm{Pb}(\mathrm{C} 7)_{2}$ converts completely into a crystal in less than $20 \mathrm{~min}$.

\section{Photoluminescence properties}

From weak fluorescence (crystal) to strong phosphorescence (glass states). The five lead(II) alkanoates display a common photophysical behaviour. Diffuse reflectance (DR) UV-vis spectra are reported in Fig. 3A and are characterized by the presence of bands in the UV region, between 200 and $280 \mathrm{~nm}$, where $6 \mathrm{~s} 6 \mathrm{p} \leftarrow 6 \mathrm{~s}^{2}$ electronic transitions occur., ${ }^{9,36}$ In the crystal phase, the compounds display a thermochromic behaviour, as emission takes place only at $77 \mathrm{~K}$, in the blue-green region of the visible spectrum (450-530 nm). All five species show a broad emission band in the aforementioned energy range as a consequence of the strong reduction of radiationless (thermal) deactivation pathways occurring at low temperatures. The emission bands display also a significant Stokes shift, typical of metal centred (MC) excited states that undergo large structural rearrangements.

Such spectral features have also been observed and reported for lead(II)-doped inorganic glasses, where broad MC-centered transitions strongly depend on the temperature and the host lattice.,

However, the luminescence of the compounds displays a significant difference depending on the phase, either crystal or glass. In this sense, the frozen glasses show intense 


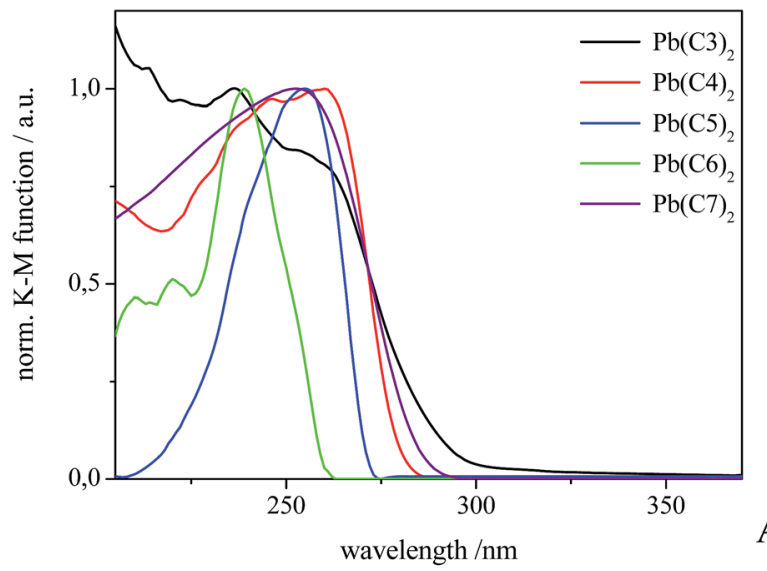

A)

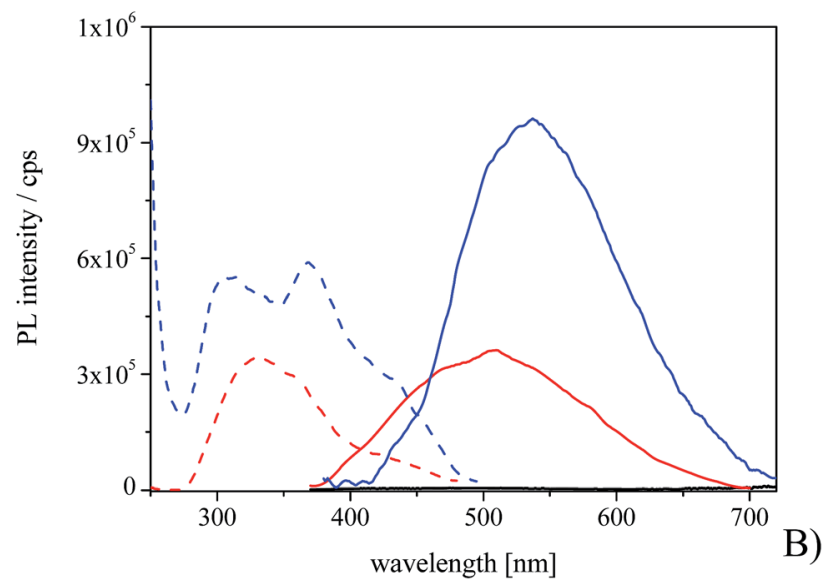

Fig. 3 (A) Diffuse reflectance UV-vis spectra of the lead(॥) compounds. (B) Photoluminescence excitation (dashed lines) and emission (solid lines) spectra of $\mathrm{Pb}(\mathrm{C} 4)_{2}$, recorded in the crystal phase at $293 \mathrm{~K}$ (black) and $77 \mathrm{~K}$ (red) and in the glass phase (blue); for the emission spectra $\lambda_{\text {exc }}=350 \mathrm{~nm}$, while for the excitation spectra $\lambda_{\mathrm{em}}=500 \mathrm{~nm}$.

luminescence at $77 \mathrm{~K}$ which persists even at RT. Thus, as inferred from the decay lifetimes, the lead(II) alkanoates in the crystal phase are basically fluorescent at low temperatures, whereas the corresponding glasses, obtained after melting the crystals and subsequently freezing the liquid phase, display clear phosphorescence, at low and also at room temperature.

The emission and excitation spectra of $\mathrm{Pb}(\mathrm{C} 4)_{2}$ are presented in Fig. 3B as a representative of the lead(II) alkanoates series (see ESI for the other compounds, Fig. S13-S16 $\dagger$ ) and the properties of the four compounds are summarized in Table 3 . It can be noted that, while the crystals are fluorescent, the glasses are phosphorescent with excited state lifetimes in the millisecond scale, except for $\mathrm{Pb}(\mathrm{C} 5)_{2}$.

The reasons for this behaviour can be attributed to different molecular organizations in the two phases, which lead to different lattice interactions. The fluorescence in the crystalline forms recalls that of some lead(II) clusters and coordination polymers, ${ }^{5,6}$ where delocalized charge-transfer cluster states of oxygen-bridged lead ions are predominant with respect to triplet MC states so that deactivation from those states successfully competes with the MC phosphorescence. The situation might be the opposite in the frozen glasses, where degrees of order are lost and more emitting centres arise. Moreover, as detected by the PDF analysis, the $\mathrm{Pb}-\mathrm{Pb}$ distances decrease considerably from the crystal (around 4.3, 4.7 and 4.9 $\AA$, in all of the compounds) to the glass states (merged at around $4.15 \AA$ ). Thus, with shortening of the distances, the electronic overlap among the metal orbitals increases, leading to enhanced spin-orbit coupling and, in turn, a higher triplet character in the emitting states that decay via phosphorescence.

In the $\mathrm{G}_{\mathrm{IL}}$ phases of $\mathrm{Pb}(\mathrm{C} 3)_{2}$ and $\mathrm{Pb}(\mathrm{C} 4)_{2}$ there would be a prevalence of isolated ${ }^{3} \mathrm{MC}$ states characterized by a very long decay dynamics, in the order of milliseconds, while for $\mathrm{Pb}(\mathrm{C} 6)_{2}$ the decay lifetime slightly decreases as orientational order appears in its $\mathrm{G}_{\mathrm{LC}}$ phase. Within this trend, the short-living phosphorescence of $\mathrm{Pb}(\mathrm{C} 5)_{2}(\sim 52 \mu \mathrm{s})$ represents a proof that obtaining a $\mathrm{G}_{\mathrm{IL}}$ phase out of it is difficult and what we observe is the emission of the rotator phase, emission that originates from a mixed charge-transfer/MC state with predominant triplet character.

Finally, the differences observed in the luminescence lifetimes are all due to the different intermolecular interactions that the compounds go through when switching from crystal to glass. However, all compounds display emission in the same

Table 3 Photophysical properties of the lead(॥) alkanoates

\begin{tabular}{|c|c|c|c|c|c|}
\hline Compound & $\begin{array}{l}\text { Absorption } \\
(\mathrm{nm})\end{array}$ & $\begin{array}{l}\text { Fluorescence } \\
\text { emission }^{a}(\mathrm{~nm})\end{array}$ & $\begin{array}{l}\text { Fluorescence } \\
\text { lifetime }^{a}(\mathrm{~ns})\end{array}$ & $\begin{array}{l}\text { Phosphorescence } \\
\text { emission }^{b}(\mathrm{~nm})\end{array}$ & $\begin{array}{l}\text { Phosphorescence } \\
\text { lifetime }^{b}(\mathrm{~ms})\end{array}$ \\
\hline $\mathrm{Pb}(\mathrm{C} 3)_{2}$ & 236,254 & 490 & $\begin{array}{l}4.63(57 \%) \\
16.26(43 \%)\end{array}$ & 545 & $\begin{array}{l}2.12(70 \%) \\
0.34(30 \%)\end{array}$ \\
\hline $\mathrm{Pb}(\mathrm{C} 4)_{2}$ & 246,260 & 508 & $\begin{array}{l}3.57(62 \%) \\
11.54(38 \%)\end{array}$ & 537 & $\begin{array}{l}2.18(62 \%) \\
0.33(38 \%)\end{array}$ \\
\hline $\mathrm{Pb}(\mathrm{C} 5)_{2}$ & 255 & 480 & $\begin{array}{l}3.52(64 \%) \\
11.83(36 \%)\end{array}$ & 484,516 & 0.052 \\
\hline $\mathrm{Pb}(\mathrm{C} 6)_{2}$ & $210,220,238$ & 517 & $\begin{array}{l}3.76(59 \%) \\
15.03(41 \%)\end{array}$ & 504 & $\begin{array}{l}1.87(77 \%) \\
0.21(23 \%)\end{array}$ \\
\hline $\mathrm{Pb}(\mathrm{C} 7)_{2}$ & 253 & 460 & $\begin{array}{l}19.66(68 \%) \\
4.32(32 \%)\end{array}$ & 479 & $\begin{array}{l}0.11(74 \%) \\
0.67(26 \%)\end{array}$ \\
\hline
\end{tabular}

${ }^{a}$ Recorded in the crystal phase at $77 \mathrm{~K} .{ }^{b}$ Recorded in the glass phase at $77 \mathrm{~K}$ and $293 \mathrm{~K}$. 
spectral region, indicating a common electronic configuration (similar orbital energy levels).

\section{Conclusions}

The detailed structural and thermal studies carried out in short lead(II) alkanoates (from propionate to heptanoate) show a complex behaviour, with different types of disorder and, therefore, different types of glass structures (regular glass, liquid crystal glass and rotator glass). The samples were analysed thoroughly and the single phases (crystal and glasses) were characterized, using diverse techniques, such as DSC, SCXRD and PXRD, PDF-analysis, UV-vis spectroscopy, C-13 and Pb-207 CP/MAS NMR and polarized light microscopy. The thermal study on these short(II) lead alkanoates has been completed in this work and the crystal structures are reported here for the first time (with the exception of $\mathrm{Pb}(\mathrm{C} 4)_{2}, \mathrm{~Pb}(\mathrm{C} 7)_{2}$, already published). Moreover, the local structure in the glass phases has been studied, so that both crystal and glass phases can be compared, as well as the relative properties. The bilayered structure is also maintained in both crystal (2D coordination polymer) and glass phases.

Thus, the main feature relies on the direct structure/luminescence relationship from the crystal to the glass state, with a great enhancement of the optical properties. The crystal phases are weakly fluorescent whereas the glass states are strongly phosphorescent. This behaviour is related to the changes in the local structures and, in particular, to the reduction of the $\mathrm{Pb}-\mathrm{Pb}$ distances from the crystal to the glasses, which favours a high orbital overlap between the heavy atoms.

The luminescence in glasses is well known for ceramic materials but not in coordination polymers or MOFs, and it would be a very interesting field to explore with other systems, such as mixed ligand compounds with different cations, in order to enhance the optical properties from the crystal to the glass state, by modifying the local structure, as it occurs in the presented short lead(II) alkanoates.

\section{Experimental}

\section{Sample preparation}

Synthesis methods for the different salts are described in detail elsewhere, ${ }^{19,25,31}$ and are valid for all of the compounds of the lead(II) alkanoates series. Crystals suitable for single crystal X-ray studies of $\mathrm{Pb}(\mathrm{C} 3)_{2}, \mathrm{~Pb}(\mathrm{C} 5)_{2}$, and $\mathrm{Pb}(\mathrm{C} 6)_{2}$ were grown up by slow evaporation from ethanol solutions (for $\mathrm{Pb}(\mathrm{C} 3)_{2}$ and $\left.\mathrm{Pb}(\mathrm{C} 5)_{2}\right)$ and benzene (for $\left.\mathrm{Pb}(\mathrm{C} 6)_{2}\right)$.

\section{Differential scanning calorimetry (DSC)}

A TA Instruments DSC Model Q10 was used in this work. Tightly sealed aluminum volatile pans (in a $\mathrm{N}_{2}$ atmosphere) were used to scan at different heating rates (in a dry nitrogen atmosphere

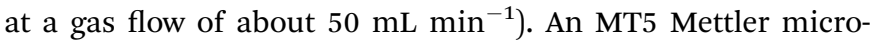
balance was used to weigh $10 \mathrm{mg}$ of each sample (error: \pm 0.001 $\mathrm{mg}$ ). The calorimeter temperature was calibrated using In and Sn standard samples supplied by TA (purity $>99.999 \%$ and
$>99.9 \%$, respectively), and benzoic acid (purity > 99.97\%), supplied by the former NBS (lot 39i). Enthalpy was calibrated using the In and Sn standards.

\section{Single crystal X-ray diffraction (SCXRD)}

Synchrotron radiation SCXRD experiments were performed with a wavelength $\lambda=0.9779$, for $\mathrm{Pb}(\mathrm{C} 3)_{2}$ and $\mathrm{Pb}(\mathrm{C} 5)_{2}$, and $\lambda=$ $0.7339 \AA$, for $\mathrm{Pb}(\mathrm{C} 6)_{2}$, at the BM16 Spanish beamline of European Synchrotron Radiation Facility (ESRF, in Grenoble, France) using a CCD detector (ADSCq210r), making phi scans while collecting the data. The oscillation range $(\Delta \varphi)$ used for each image was one degree. $\mathrm{Pb}(\mathrm{C} 3)_{2}$ was measured at $\mathrm{RT}$, and the other compounds at $100 \mathrm{~K}$. The crystals, solved and refined using the SHELXS-97 and SHELXL-97 programs, ${ }^{37}$ suffered severe radiation damage in all of the cases which, together with the great difficulty in obtaining good crystals (due to a weak bonding between lipidic layers), makes the data statistics obtained by SCXRD not as good as desirable for small molecules. However, these data are reliable and, as a proof of it, high resolution powder diffraction was performed to confirm the structures by the Rietveld method (using the FullProf ${ }^{38}$ program). The experimental parameters, crystal sizes, and main crystallographic data for the compounds studied are shown in the ESI. $\dagger$

\section{High-energy X-ray total scattering and PDF analysis}

Finely powdered dry samples of the lead(II) salts were loaded into $1.0 \mathrm{~mm}$ diameter Kapton capillaries. High-energy X-ray total scattering data acquisition was performed at beamline ID15B, at the ESRF. Scattering data were collected with a Mar133 CCD-detector using the Rapid-Acquisition Pair Distribution Function technique. ${ }^{39}$ Samples, an empty capillary and the background were measured at RT from $0-25.0 \AA^{-1}$. The $\mathrm{X}$-ray wavelength was refined using a $\mathrm{CeO}_{2}$ standard $(\lambda=0.1419$ $\AA)$. Corrections for sample-detector distance, tilt angle of the detector with respect to the direction of the incident radiation and polarization were performed using Fit2D. ${ }^{40}$ Total scattering structure factors and pair distribution functions (PDFs) were obtained using the PDFGetX3 software. ${ }^{41}$

\section{UV-vis spectroscopy}

UV-visible diffuse reflectance spectra were recorded using a Perkin-Elmer Model Lambda 900 spectrophotometer, equipped with a diffuse reflectance sphere accessory (DR-UV-vis). Prior to the analysis, the solid compounds were dispersed in an anhydrous BaSO4 matrix (10\% in weight).

Steady-state emission spectra were recorded on a Horiba Jobin Yvon Model IBH FL-322 Fluorolog 3 spectrometer equipped with a $450 \mathrm{~W}$ xenon arc lamp, double-grating excitation and emission monochromators $\left(2.1 \mathrm{~nm} \mathrm{~mm}{ }^{-1}\right.$ dispersion; 1200 grooves per $\mathrm{mm}$ ) and a Hamamatsu Model R928 photomultiplier tube. Emission and excitation spectra were corrected for source intensity (lamp and grating) and emission spectral response (detector and grating) by standard correction curves. Time-resolved measurements up to $\sim 5 \mu$ s were performed using the time-correlated single-photon counting (TCSPC) option on 
the Fluorolog 3 spectrometer. A NanoLED (370 nm; full width at half maximum (fwhm) $=1.2 \mathrm{~ns}$ ) with repetition rates between $10 \mathrm{kHz}$ and $1 \mathrm{MHz}$ was used to excite the sample. The excitation source was mounted directly on the sample chamber at $90^{\circ}$ to a double-grating emission monochromator $\left(2.1 \mathrm{~nm} \mathrm{~mm}^{-1}\right.$ dispersion; 1200 grooves per $\mathrm{mm}$ ) and signals were collected using an IBH Data Station Hub photon counting module. Data analysis was performed using the commercially available DAS6 software (Horiba Jobin Yvon IBH). For excited state lifetimes $>5$ $\mu \mathrm{s}$, a SpectraLED was used as the excitation source (460 nm; fwhm $=1.2 \mathrm{~ns}$ ) and data collection and analysis was made as described above.

The samples, in the crystal and glass phases, were measured at $77 \mathrm{~K}$ and at RT.

\section{Acknowledgements}

Partial support of this research by the Project CTQ2008-06328/ BQU, by the Spanish Ministerio de Ciencia e Innovación, is gratefully acknowledged. F.J.M.C. acknowledges the JAE-DOC postdoctoral contracts by CSIC and by Max IV Laboratory. L.G. also acknowledges the financial support provided by CSIC. F.C. acknowledges Regione Piemonte for the postdoctoral fellowship. The authors would like to thank the beamlines BM16-LLS, BM25-Spline and ID15B (ESRF, Grenoble, France), and their staff, and the CAI's (Centro de Asistencia a la Investigación) of XRD of the UCM, and their staff, for the use of their technical facilities and help.

\section{Notes and references}

1 (a) D. M. Poojary, B. Zhang, A. Cabeza, S. Bruque, M. A. G. Aranda and A. Clearfield, J. Mater. Chem., 1996, 6, 639; (b) J.-G. Mao, Z. Wang and A. Clearfield, Inorg. Chem., 2002, 41, 6106; (c) J.-G. Mao, Z. Wang and A. Clearfield, J. Chem. Soc., Dalton Trans., 2002, 24, 4541; (d) M. M. GomezAlcantara, A. Cabeza, M. A. G. Aranda, A. Guagliardi, J.-G. Mao and A. Clearfield, Solid State Sci., 2004, 6, 479.

2 (a) S. Ayyappan, G. D. Delgado, A. K. Cheetham, G. Fe'rey and C. N. R. Rao, J. Chem. Soc., Dalton Trans., 1999, 17, 2905; (b) N. Stock, Solid State Sci., 2002, 4, 1089; (c) D. T. Tran, Y. S. Kam, P. Y. Zavalij and S. R. Oliver, J. Inorg. Chem., 2003, 42, 2165; (d) E. Irran, T. Bein and N. Stock, J. Solid State Chem., 2003, 173, 293.

3 (a) Z.-M. Sun, J.-G. Mao, Y.-Q. Sun, H.-Y. Zeng and A. Clearfield, New J. Chem., 2003, 27, 1326; (b) B.-P. Yang, J.-G. Mao, Y.-Q. Sun, H.-H. Zhao and A. Clearfield, Eur. J. Inorg. Chem., 2003, 23, 4211; (c) S.-M. Ying, J.-G. Mao, B.-P. Yang and Z.-M. Sun, Inorg. Chem. Commun., 2003, 6, 1319; (d) B.-P. Yang, Z.-M. Sun and J.-G. Mao, Inorg. Chim. Acta, 2004, 357, 1583.

4 (a) W. C. De Gruijter and T. Bokx, J. Solid State Chem., 1973, 6, 271; (b) A. Strasser and A. Vogler, Inorg. Chem. Commun., 2004, 7, 528; (c) A. Strasser and A. Vogler, J. Photochem. Photobiol., A, 2004, 165, 115; (d) Z.-H. Lei, X. Li and L.-N. Dong, Inorg. Chem. Commun., 2010, 13, 1383; (e) Q. Y. Liu and L. Xu, Eur. J. Inorg. Chem., 2006, 8, 1620; (f)
X. Zhu, X. Li, Q. Liu, J. Lü, Z. Guo, J. He, Y. Li and R. Cao, J. Solid State Chem., 2007, 180, 2386.

5 (a) E. Erdogmus, E. Korkmaz and V. E. Kafadar, J. Appl. Spectrosc., 2014, 80, 945; (b) G. Lin, G. Dong, X. Liu, Q. Zhang, D. Chen and J. Qiu, Electrochem. Solid-State Lett., 2010, 13, J1; (c) H. F. Folkerts, F. Ghianni and G. Blasse, J. Phys. Chem. Solids, 1996, 57, 1659.

6 (a) M. Mehnaoui, G. Panczer, R. Ternane, M. Trabelsi-Ayedi and G. Boulon, Opt. Mater., 2008, 30, 1672; (b) A. A. Bol and A. Meijerink, Phys. Chem. Chem. Phys., 2001, 3, 2105; (c) F. Gu, M. K. Lu, S. F. Wang, Y. X. Qi, C. F. Song, G. J. Zhou, D. Xu and D. R. Yuan, Appl. Phys. A, 2004, 78, 1059; (d) H. F. Folkerts, M. A. Hamstra and G. Blasse, Chem. Phys. Lett., 1995, 246, 135.

7 K. Dutta and M. W. Perkovic, Inorg. Chem., 2002, 41, 6938.

8 F. J. Martínez Casado, L. Cañadillas-Delgado, F. Cucinotta, A. Guerrero-Martínez, M. Ramos Riesco, L. Marchese and J. A. R. Cheda, CrystEngComm, 2012, 14, 2660.

9 H. D. Burrows, Mater. Lett., 1988, 6, 191.

10 K. Binnemans, L. Jongen and C. Gorler-Wallrand, Phys. Chem. Chem. Phys., 2001, 3, 4796.

11 (a) F. J. Martínez Casado, M. Ramos Riesco, M. V. García Pérez, M. I. Redondo Yélamos, S. López-Andrés and J. A. R. Cheda, J. Phys. Chem. B, 2009, 113, 12896; (b) F. J. Martínez Casado, M. Ramos Riesco, I. Da Silva, A. Labrador, M. I. Redondo, M. V. García Pérez, S. LópezAndrés and J. A. R. Cheda, J. Phys. Chem. B, 2010, 114, 10075; (c) F. J. Martínez Casado, M. Ramos Riesco, I. Da Silva, M. I. Redondo and J. A. R. Cheda, RSC Adv., 2011, 1, 147.

12 F. J. Martínez Casado, M. Ramos Riesco, M. I. Redondo, A. Sánchez Arenas and J. A. R. Cheda, J. Therm. Anal. Calorim., 2012, 108, 399.

13 B. Wunderlich, M. Möler, J. Grebowicz and H. Baur, Conformational Motion and Disorder in Low and High Molecular Mass Crystals, in Advances in Polymer Science. Number 87, ed. H. Höcker, Springer-Verlag, Heidelberg, 1988.

14 B. Wunderlich, Thermochim. Acta, 1999, 37, 340.

15 M. Descamps, N. T. Correia, P. Derolled, F. Danede and F. Capet, J. Phys. Chem. B, 2005, 109, 16092.

16 P. J. Collings and J. S. Patel, Handbook of Liquid Crystal Research, Oxford University Press, New York, 1997.

17 A. Habenschuss, M. Varma-Nair, Y. K. Kwon, J. Ma and B. Wunderlich, Polymer, 2006, 47, 2369.

18 F. J. Martínez Casado, M. Ramos Riesco, A. Sánchez Arenas, M. V. García Pérez, M. I. Redondo, S. López-Andrés, L. Garrido and J. A. R. Cheda, J. Phys. Chem. B, 2008, 112, 16601.

19 F. J. Martínez Casado, M. Ramos Riesco, I. Da Silva, M. I. Redondo, A. Labrador and J. A. R. Cheda, Cryst. Growth Des., 2011, 11, 759.

20 F. Lacouture, M. Francois, C. Didierjean, J. P. Rivera, E. Rocca and J. Steinmetza, Acta Crystallogr., Sect. C: Cryst. Struct. Commun., 2001, 57, 530.

21 C. G. Bazuin, D. Guillon, A. Skoulios, A. M. Amorim da Costa, H. D. Burrows, C. F. G. C. Geraldes, J. J. C. Teixeira-Dias, E. Blackmore and G. J. T. Tiddy, Liq. Cryst., 1988, 3, 1655. 
22 J. Schwede, L. Koehler, H. P. Grossmann, M. Pietralla and H. D. Burrows, Liq. Cryst., 1994, 16, 267.

23 H. A. Ellis and J. W. C. de Vries, Mol. Cryst. Liq. Cryst., 1988, 163, 133.

24 A. M. Amorim da Costa, H. D. Burrows, C. F. C. G. Geraldes, J. J. C. Teixeira-Dias, C. G. Bazuin, D. Guillon, A. Skoulios, E. Blackmore, G. J. T. Tiddy and D. L Turner, Liq. Cryst., 1986, 1, 215.

25 A. Sánchez Arenas, M. V. García, M. I. Redondo, J. A. R. Cheda, M. V. Roux and C. Turrión, Liq. Cryst., 1995, 18, 431 .

26 S. A. Adeosun and S. J. Sime, Thermochim. Acta, 1978, 27, 319.

27 M. E. Ekwunife, M. U. Nwachukwu, F. P. Rinehart and S. Sime, J. Chem. Soc., Faraday Trans. 1, 1975, 71, 1432.

28 F. J. Martínez Casado, M. V. García Pérez, M. I. Redondo Yélamos, J. A. R. Cheda, A. Sánchez Arenas, S. López de Andrés, J. García-Barriocanal, A. Rivera, C. León and J. Santamaría, J. Phys. Chem. C, 2007, 111, 6826.

29 K. R. Seddon, A. Stark and M. J. Torres, Pure Appl. Chem., 2000, 72, 2275.

30 J. D. Holbrey and K. R. Seddon, Ionic Liq., 1999, 1, 232.

31 F. J. Martínez-Casado, A. Sánchez Arenas, M. V. García Pérez, M. I. Redondo Yélamos, S. López de Andrés and J. A. R. Cheda, J. Chem. Thermodyn., 2007, 39, 455.
32 J. A. Duffy and M. D. Ingram, J. Am. Ceram. Soc., 1969, 52, 224.

33 M. D. Ingram, G. G. Lewis and J. A. Duffy, J. Phys. Chem., 1972, 76, 1035.

34 R. F. Bartholomew and S. S. Lewek, J. Am. Ceram. Soc., 1970, $56,445$.

35 F. J. Martínez Casado, M. Ramos Riesco, M. I. Redondo, S. López-Andrés and J. A. R. Cheda, Cryst. Growth Des., 2011, 11, 1021.

36 T. Tsuboi, M. J. Stillman and P. W. M. Jacobs, Chem. Phys. Lett., 1980, 74, 135.

37 G. M. Sheldrick, Acta Cryst. A, 2008, 64, 112.

38 (a) J. Rodríguez-Carvajal, Phys. B, 1993, 192, 55; (b) J. Rodríguez-Carvajal, Commission on Powder Diffraction (IUCr). Newsletter, 2001, vol. 26, p. 12.

39 P. J. Chupas, X. Y. Qiu, J. C. Hanson, P. L. Lee, C. P. Grey and S. J. L. Billinge, J. Appl. Crystallogr., 2003, 36, 1342.

40 (a) A. P. Hammersley, S. O. Svensson, M. Hanfland, A. N. Fitch and D. Hausermann, High Pressure Res., 1996, 14, 235; (b) Fit2D V9.129 Reference Manual V. 3.1, A. P. Hammersley In ESRF Internal Report, ESRF98HA01T, 1998.

41 P. Juhás, T. Davis, C. L. Farrow and S. J. L. Billinge, J. Appl. Crystallogr., 2013, 46, 560. 